\title{
SEPARATORS FOR SLAC B-FACTORY
}

\author{
A.D. Chernyakin, V.N. Eschenko, V.F. Gourko, V.N. Karasyuk, A.D. Khilchenko, A.N. Kvashnin, \\ Yu.M Kolokolnikov, M.V. Petrichenkov, G.I. Silvestrov, G.S. Villevald, V.G. Volokhov, BINP, \\ Novosibirsk, Russia \\ D. MacNair, J. Minister, V. Nesterov, U. Wienands, Z. Wolf; SLAC, Stanford, USA
}

\section{Abstract}

In order to separate the beams during injection, a closed vertical bump will be introduced in the B-Factory High Energy Ring (HER) using four dedicated, pulsed magnets. The design field in the magnets is $\mathrm{B}_{0}=660 \mathrm{G}$; the field integrals of the magnets are nominally:

$$
\begin{array}{lll}
\int \mathrm{Hdl}=0.0450 \mathrm{~T} \cdot \mathrm{m} ; & \int \mathrm{Hdl}=0.0420 \mathrm{~T} \cdot \mathrm{m} ; \\
\int \mathrm{Hdl}=0.0756 \mathrm{~T} \cdot \mathrm{m} ; & \int \mathrm{Hdl}=0.0832 \mathrm{~T} \cdot \mathrm{m}
\end{array}
$$

The magnet apertures are $15 \mathrm{~cm}$ horizontal along the field direction and $10 \mathrm{~cm}$ in the vertical direction. The beams will be separated with a rise time of about $200 \mathrm{~ms}$ at the end of a coast and brought back into collision within about 1 ms. A good-field-region of $\pm 4.1 \mathrm{~cm}$ in the horizontal and $\pm 2.1 \mathrm{~cm}$ in the vertical direction with field non-uniformity less than $0.2 \%$ is aimed for, and fast magnetic field switch-off even through the present steel vacuum pipe of about $4 \mathrm{~mm}$ thickness. A $15 \%$ variation in each magnet current is done with variable shunts to allow tuning of the bump for different lattice configurations. The magnets have to fit into the existing constrained space of the B-factory.

The magnets have been made and tested successfully at BINP and at SLAC. The whole system including pulsed power supply and shunts were also tested successfully.

\section{MAGNETS}

The beam separation in the interaction point will be realized by means of two pairs of magnets. These magnets have the specific geometry not typical for the dipole magnets applied in accelerators. The aperture of separators is defined by size of existing vacuum chamber. Their outer dimensions are defined by limited space on Bfactory, so magnets dimensions should not be much bigger than their aperture. Usual magnets as a rule have an aperture $A_{x}$ (along the field) much less than $A_{y}$. So, the surfaces of ferromagnetic poles play the main role in field forming inside the aperture. In our case $A_{x}>A_{y}$ and coils are placed inside the aperture, so their geometry has the main influence on field topography. Really the $0.2 \div 0.3 \mathrm{~mm}$ coils shift along the field direction can change the region of $0.2 \%$ field uniformity by $\sim 1 \mathrm{~cm}$. But the field topography is not affected substantially by $0.1 \mathrm{~mm}$ coil shift. This is the accuracy of coils positioning. Magnets were adjusted during magnetic measurements.

During measurements the effective edge location relative to geometrical edge of the magnet's yoke was determined for the real geometry of the face part of the coils. The preliminary calculations of edge fields were made using special computer code MERMAID for 3D field computations and gave the effective edge length $\Delta_{\text {eff }}=6.1 \mathrm{~cm}$. Therefore the geometrical length of yoke of each magnet was made less by $12 \mathrm{~cm}$ than it's given magnetic length. The results of measurements are given below in Table 1. The cross-section of the magnet is shown in Fig. 1.

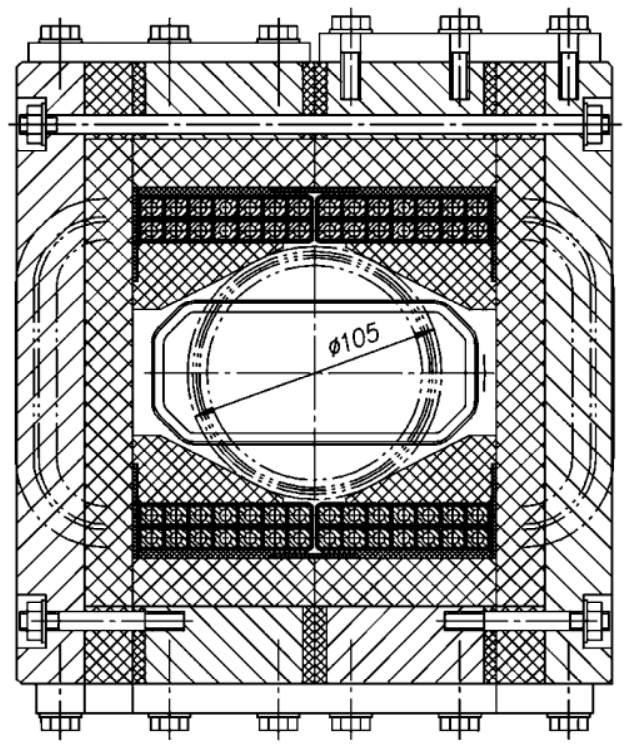

Fig.1 Magnet cross-section with two types of vacuum chamber.

Table 1
\begin{tabular}{|c|c|c|c|}
\hline$\#$ & $\begin{array}{c}\Delta_{\text {eff }} \text { from the } \\
\text { current } \\
\text { leads side, cm }\end{array}$ & $\begin{array}{c}\Delta_{\text {eff, from }} \\
\text { another } \\
\text { side, cm }\end{array}$ & $\begin{array}{c}\text { Total magnetic } \\
\text { length, cm }\end{array}$ \\
\hline 1 & 6.0 & 5.6 & 63.6 \\
\hline 2 & 6.0 & 5.5 & 67.5 \\
\hline 3 & 5.9 & 5.6 & 124.5 \\
\hline 4 & 6.0 & 5.1 & 113.1 \\
\hline
\end{tabular}

\section{POWER SUPPLY}

Below all the discussions are referred to the switching off time of $1 \mathrm{~ms}$. With an increase of the chamber wall 
thickness the magnetic fields starts to delay in phase from the current exciting the field. The field in the magnet aperture is determined by two components. The first component is the law of current change through the winding. The second component is the attenuation process according to the exponential law which is only determined by geometry and chamber wall thickness:

$$
H(t)=H_{\text {max }} \cdot e^{-\gamma t}, \text { where } \gamma=\frac{c^{2}}{2 \pi \sigma \alpha d},
$$

where $\alpha$ - is the radius of the vacuum chamber; $d$ - is the vacuum chamber thickness; $\sigma-$ is the specific conductance of the vacuum chamber material; $c-$ is the velocity of light.

Besides the analytical calculations of magnetic field diffusion through the wall of vacuum chamber the experimental measurements on the model have been undertaken. During measurements the wall thickness and material of vacuum chamber were varied. The power supply source with duration of leading edge enough for the imitation of constant magnet supply was built. The trailing edge of this pulse provides the field fade according to the relation $\mathrm{H}(\mathrm{t})=\mathrm{H}_{\max } \cdot \cos (\pi \mathrm{t} / \tau)$, where $\tau / 2=1 \mathrm{~ms}-$ is half sine duration of trailing edge. The corresponding curves of exciting current and magnetic field inside the aperture in presence of vacuum chamber are shown in Fig. 2a,b,c ( a - stainless steel, 0.5 mm thick; $\mathrm{b}$-stainless, $5 \mathrm{~mm}$ thick; c-copper, $0.5 \mathrm{~mm}$ thick copper chambers). Investigations have shown that the use of $5 \mathrm{~mm}$ stainless steel chamber in SLAC would not allow the required fields control in magnets in transitional mode by active correction system. One can see (Fig. 2) that at the moment of zero current in the coils the field value is $\sim 23 \%$ of its maximal value, but at this moment the power supply and correction systems

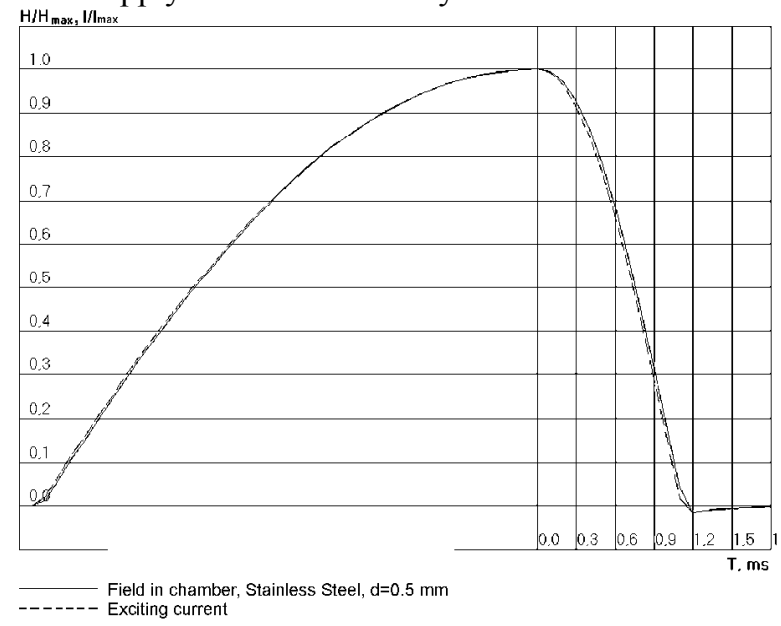

Fig. 2a Time dependence of magnetic field inside vacuum chamber and exciting current curve.

are turned off and the field fade rate inside the vacuum chamber is defined by its geometry. If all the magnets were of the same length and had the same geometry of vacuum chambers it would not cause the undesirable effects, possibly.

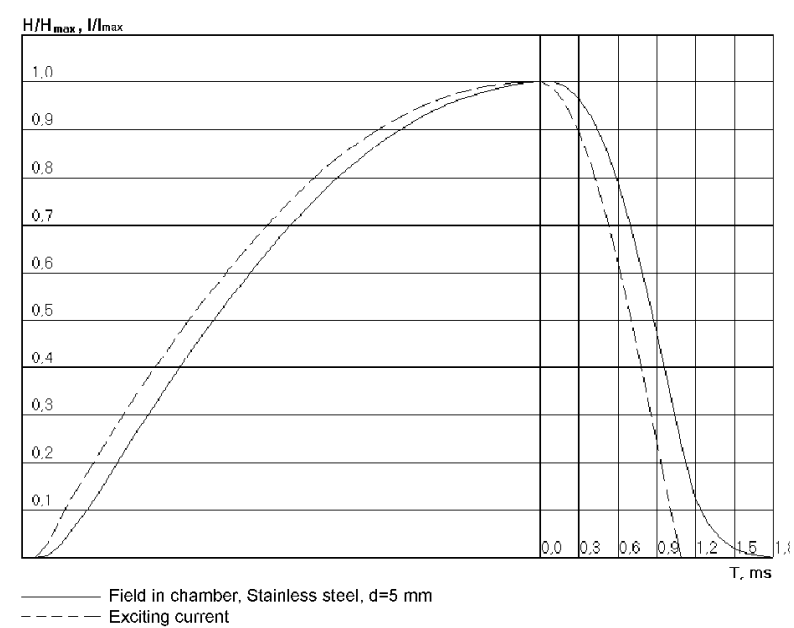

Fig. $2 b$ Time dependence of magnetic field inside vacuum chamber and exciting current curve.

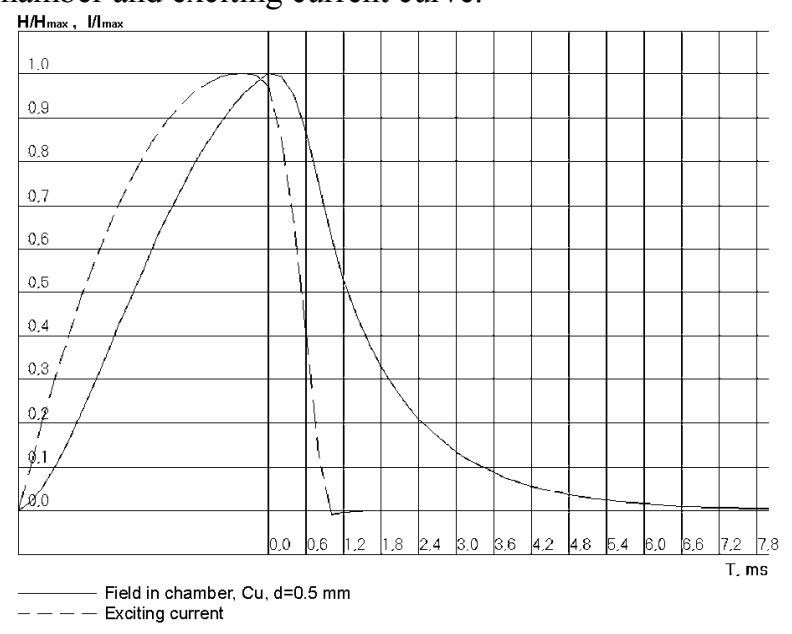

Fig. 2c Time dependence of magnetic field inside vacuum chamber and exciting current curve.

However the separator magnets have different lengths and geometry of vacuum chambers which leads to different time constants of exponential field fade and violates the synchronism. It can result in beam loss. Below the method of passive fields correction in magnets aperture during the transition process is described. The system has been proposed in which the natural exponential field fade process inside the vacuum chamber is summarized with exponential current fade in the magnet coils generated by power circuit of correction system.

The simplified diagram of separators power supply is shown in Fig. 3. It performs active correction of currents in coils in constant mode and passive correction during the transition regime. The operation sequence is the following: IGBT transistors $\mathrm{T}_{0} \div \mathrm{T}_{4}$ are being turned on during the beam separation. The current in coils of four magnets $\mathrm{L}_{0} \div \mathrm{L}_{4}$ and in parasitic feeder inductance $\mathrm{L}_{0}$ is being increased with time constant defined by properties of power source $\mathrm{E}$ and proper time constant of the load. The necessary values of correction currents are set by MOSFET transistors $\mathrm{T}_{1}^{\prime} \div \mathrm{T}_{4}^{\prime}$. During the beam convergence the IGBT transistors are being turned off and simultaneously the active current correction circuits are 
being switched off through $\mathrm{D}_{6} \div \mathrm{D}_{9}$ diodes. Thyristors $\mathrm{S}_{1} \div \mathrm{S}_{4}$ are being triggered and create the circuit for current accumulated in feeder $\mathrm{L}_{0}$. Energy stored in the feeder $\mathrm{L}_{0}$ is dissipated on its own active resistance by current flowing in circuit: feeder $\mathrm{L}_{0}-\mathrm{S}_{1} \div \mathrm{S}_{4}$ thyristors - diode $\mathrm{D}_{0}$. At the same time the reverse voltages appear on the coils of four magnets and trigger power diodes $\mathrm{D}_{1} \div \mathrm{D}_{4}$ and the exciting currents become closed by crowbar resistors $\mathrm{R}_{1}{ }^{\prime} \div \mathrm{R}_{4}{ }^{\prime}$. The values of active resistances of crowbar contactors are selected so to obtain the synchronous fade of magnetic field in each magnet with inserted vacuum chamber. The time of current switching from the coils to crowbars and from feeder $\mathrm{L}_{0}$ by $\mathrm{S}_{1} \div \mathrm{S}_{4}$ thyristors is less than $1 \mu \mathrm{s}$. Therefore at first, the power diodes $\mathrm{D}_{1} \div \mathrm{D}_{4}$ and $\mathrm{S}_{1} \div \mathrm{S}_{4}$ thyristors have been chosen with admissible current rate not less than $800 \mathrm{~A} / \mu \mathrm{s}$. Secondly, the inductance of intercepting circuits are made minimal in order to speed up the triggering process. The triggering of $\mathrm{S}_{1} \div \mathrm{S}_{4}$ thyristors is realized not by the external circuit but is generated automatically by the interception circuit itself. It eliminates possible emergency situation and damage of correction units if control signals would be missed during operation.

The more detailed descriptions are given in $[1 \div 4]$

The magnets and power supply system were made and tested at BINP and mounted on accelerator at SLAC. Magnets were tested at SLAC, the magnetic field quality and operation with exciting current up to $300 \mathrm{~A}$ were checked. The correction system was tested with current up to $50 \mathrm{~A}$. The synchronism of magnetic field fade was tested also. The results of testing have convinced that the system can be used for the designed aim.

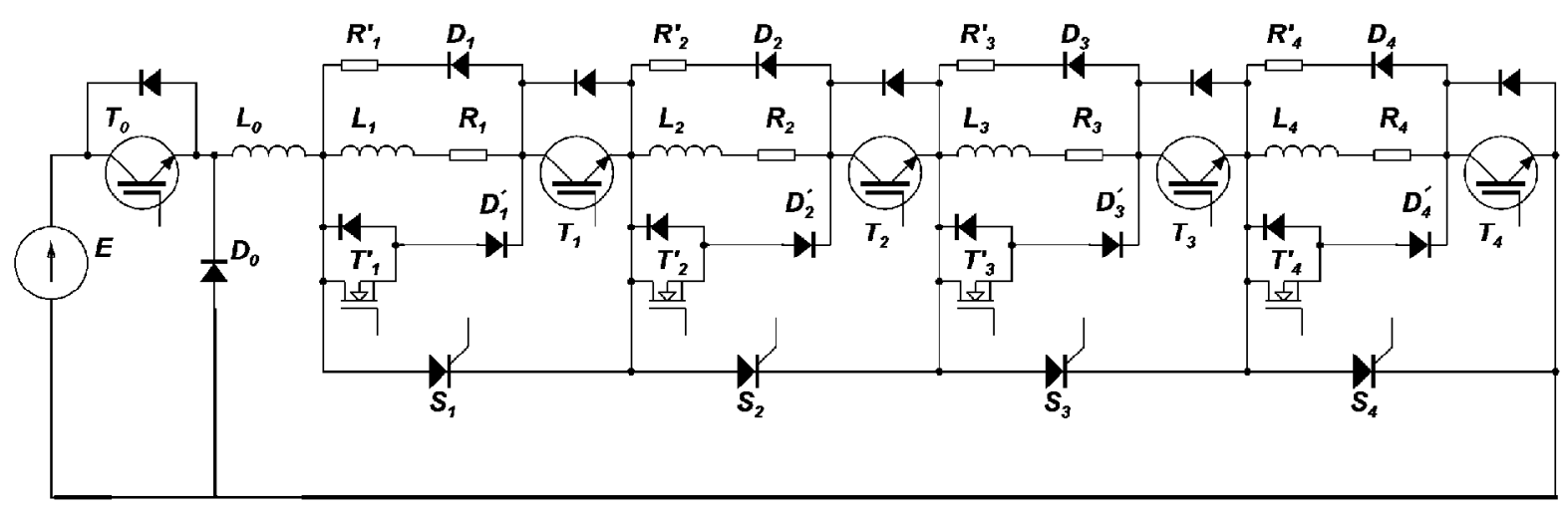

Figure $3 \mathrm{E}$ - Power Supply (375 A, $80 \mathrm{~V}) ; \mathrm{T}_{0}-\mathrm{T}_{4}$ - transistors IGBT (400 A, $\left.1700 \mathrm{~V}\right) ; \mathrm{S}_{1}-\mathrm{S}_{4}-\mathrm{SCR}-\mathrm{s}(100 \mathrm{~A}, 800 \mathrm{~V}) ; \mathrm{D}_{0}$, $\mathrm{D}_{1}-\mathrm{D}_{4}, \mathrm{D}_{1}{ }_{1}-\mathrm{D}_{4}^{\prime}$ - diodes $(80 \mathrm{~A}, 1200 \mathrm{~V}) ; \mathrm{T}_{1}^{\prime}-\mathrm{T}_{4}{ }^{\prime}-$ MOSFET-transistors $(180 \mathrm{~A}, 100 \mathrm{~V}) ; \mathrm{R}_{1}{ }_{1}-\mathrm{R}_{4}^{\prime}-$ crowbar resistors; $\mathrm{L}_{0}=$ $250 \mu \mathrm{H}$ - parasitic inductance of feeder; $\mathrm{L}_{1}=846 \mu \mathrm{H}$ - inductance of the $1^{\text {st }}$ magnet; $\mathrm{R}_{1}=35.8 \mathrm{mOhm}$ - resistance of the $1^{\text {st }}$ magnet; $\mathrm{L}_{2}=785 \mu \mathrm{H}$ - inductance of the $2^{\text {nd }}$ magnet; $\mathrm{R}_{2}=33.2 \mathrm{mOhm}-$ resistance of the $2^{\text {nd }}$ magnet; $\mathrm{L}_{3}=470 \mu \mathrm{H}$ - inductance of the $3^{\text {st }}$ magnet; $\mathrm{R}_{3}=22 \mathrm{mOhm}$ - resistance of the $3^{\text {st }}$ magnet; $\mathrm{L}_{4}=440 \mu \mathrm{H}$ - inductance of the $4^{\text {th }}$ magnet; $\mathrm{R}_{4}=21.2 \mathrm{mOhm}$ resistance of the $4^{\text {th }}$ magnet, $\mathrm{R}_{1}{ }^{\prime}=3.065 \mathrm{Ohm}-$ crowbar resistance of the $1^{\text {st }}$ magnet, $\mathrm{R}_{2}{ }^{\prime}=2.925 \mathrm{Ohm}-$ crowbar resistance of the $2^{\text {nd }}$ magnet, $\mathrm{R}_{3}{ }^{\prime}=1.87 \mathrm{Ohm}-$ crowbar resistance of the $3^{\text {st }}$ magnet, $\mathrm{R}_{4}{ }^{\prime}=1.80 \mathrm{Ohm}-$ crowbar resistance of the $4^{\text {th }}$ magnet.

\section{REFERENCES}

[1] A. Chernyakin et al "Passive Corrector of the separating magnet current", BINP, 2000

[2] A. Chernyakin et al "HER Beam Separator" BINP, 1999
[3] A. Chernyakin et al "Investigation of the Static and Pulsed Magnetic Field of the SLAC Separator", BINP, 2000

[4] V. Karasyuk et al "Investigations of fields in beam separator magnets", BINP, 2000 